\title{
Adipose-derived mesenchymal stromal cells for chronic myocardial ischemia (MyStromalCell Trial): study design
}

Adipose tissue represents an abundant, accessible source of multipotent adipose-derived stromal cells (ADSCs). Animal studies have suggested that ADSCs have the potential to differentiate in vivo into endothelial cells and cardiomyocytes. This makes ADSCs a promising new cell source for regenerative therapy to replace injured tissue by creating new blood vessels and cardiomyocytes in patients with chronic ischemic heart disease. The aim of this special report is to review the present preclinical data leading to clinical stem cell therapy using ADSCs in patients with ischemic heart disease. In addition, we give an introduction to the first-in-man clinical trial, MyStromalCell Trial, which is a prospective, randomized, double-blind, placebo-controlled study using culture-expanded ADSCs obtained from adipose-derived cells from abdominal adipose tissue and stimulated with VEGF-A ${ }_{165}$ the week before treatment.

\begin{abstract}
KEYWORDS: adipose-derived stromal cell adipose tissue cardiac repair chronic ischemic heart disease double-blind intramyocardial injection mesenchymal stem cell mesenchymal stromal cell MyStromalCell Trial placebo-controlled trial randomized vascular endothelial growth factor
\end{abstract}

Despite advances in medical treatment and surgical and percutaneous interventions, there is still a group of patients who suffer from refractory angina or angina-equivalent dyspnea due to myocardial ischemia. Chronic myocardial ischemia is a result of a gradually occluded or significantly blocked coronary artery. Distal to the blockage, the formation of collateral vessels is an attempt to maintain the perfusion to the ischemic area. Frequently, however, this attempt from the body's own endogenous mechanisms is inadequate and the results are myocardial hypoperfusion, loss of functional cardiomyocytes, diastolic and systolic dysfunction and finally angina or angina-equivalent dyspnea [1].

The attempt to find a new treatment for these patients with refractory angina or angina-equivalent dyspnea, in spite of maximal treatment with conventional therapies, has led researchers to investigate the potential of regenerative medicine using autologous or allogeneic stem cells isolated from different tissues [2].

Stem cells isolated from adipose tissue have been suggested as a new cell source for regenerative medicine within cardiology [3]. Presently, only this clinical trial using culture-expanded adipose-derived stromal cells (ADSCs) in patients with heart disease is registered in the clinical trial database (NCT01449032) [101]. However, there are two registered clinical trials using freshly isolated adipose-derived cells
(ADCs) in patients with ischemic heart failure: the PRECISE study and, in patients with acute myocardial infarction, the APOLLO study (NCT00426868 and NCT00442806, respectively).

This article reviews the isolation and characterization of ADSCs and preclinical animal studies using ADSCs in experimental ischemic heart disease. In addition, it introduces the first-in-man prospective, randomized, double-blind, placebo-controlled clinical trial, MyStromalCell Trial, using VEGF- $A_{165}{ }^{-}$ stimulated autologous ADSCs in patients with chronic ischemic heart disease and refractory angina.

\section{Adipose-derived stromal cells}

Adipose tissue is a mesodermally derived organ that consists of adipocytes of various sizes. Interspersed between these mature adipocytes is the stroma, which is itself composed of endothelial cells, smooth muscle cells, fibroblasts, leukocytes, macrophages and preadipocytes [4]. Zuk et al. were the first to isolate and identify a fraction of ADCs containing stem cells, also called the stromal vascular fraction [5]. ADCs contain an abundant population of multipotent ADSCs, approximately $2 \%$ of nucleated cells [6], which is in concentrations approximately 100-300-times higher than the concentration of mesenchymal stromal cells (MSCs) in bone marrow [7]. It has been demonstrated that these

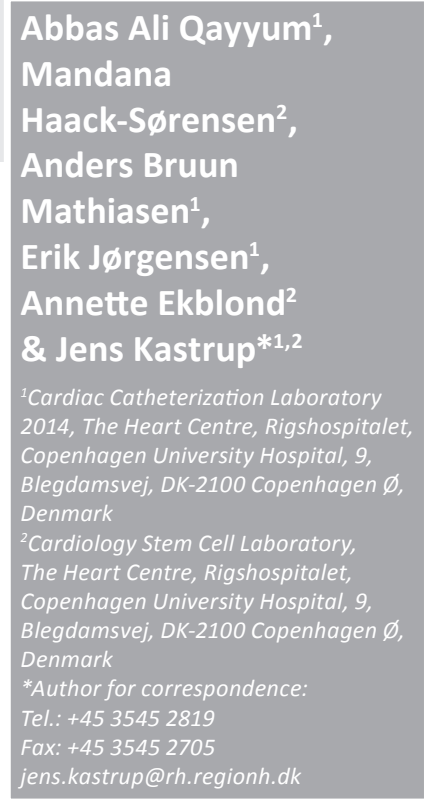

Future Medicine part of 
ADSCs have similar extensive proliferative and multilineage potential as bone marrow-derived MSCs [6,8-10]. However, to reach a sufficient number of ADSCs for clinical use, it is necessary to culture expand the cells for several weeks.

Due to the easily accessible anatomical location and the abundant existence of subcutaneous adipose tissue in the abdominal region, ADSCs hold the advantage of a simple and less invasive harvesting technique. Adipose tissue normally allows extraction of a large volume of tissue with limited morbidity under local anesthesia [6]. For cell-based therapies, the large number of stem cells that can be harvested within a single surgical procedure is an advantageous approach that reduces extensive and costly in vitro culture expansion (Figure 1) [11].

\section{Cell surface characterization of ADSCs}

The cell surface phenotype of human ADSCs is quite similar to MSCs [12]. Several studies have been carried out to define the surface markers of the ADSC phenotype, but this issue is still quite controversial. On the surface of ADSCs, CD105, CD90, CD73, CD166, CD13, CD29, CD44, CD49e, CD51 and HLA-ABC markers have been found with highly consistent patterns of expression [6,12,13]. However, Gronthos et al. showed that markers such as CD49d, CD9, CD34, CD105 and CD166 are present at much lower levels [14]. Other studies report that the immunophenotype of the ADSCs changes progressively with adherence and passage. The expression of CD166, CD90, CD73, CD13, CD44 and CD29 is initially low on ADSCs and increases significantly with successive passages and becomes stable after passage p2 [15]. The presence or absence of Stro-1 is particularly controversial. In fact, there are studies that report the absence of this marker in ADSC cultures [14], while others report its presence [6,13].

ADSCs lack the expression of known hematopoietic and endothelial markers such as CD3, CD4, CD11c, CD14, CD15, CD16, CD19, CD31, CD33, CD38, CD 45, CD56, CD62p, CD104, CD106 and CD144. Less than $1 \%$ of ADSCs express the HLA-DR protein, which makes these cells suitable for allogeneic transplantation without the risk of rejection [6,13].

Regarding CD34 and CD106, Gronthos et al. found these markers in ADSCs [14], while Zuk et al. report their absence [13]. However, Katz et al. found these markers to be absent or expressed only on a negligible numbers of cells [12]. These contradictory results may be explained by the use of different isolation and cultivation protocols and differences in marker antibodies, sources and detection methods used in the referred studies.

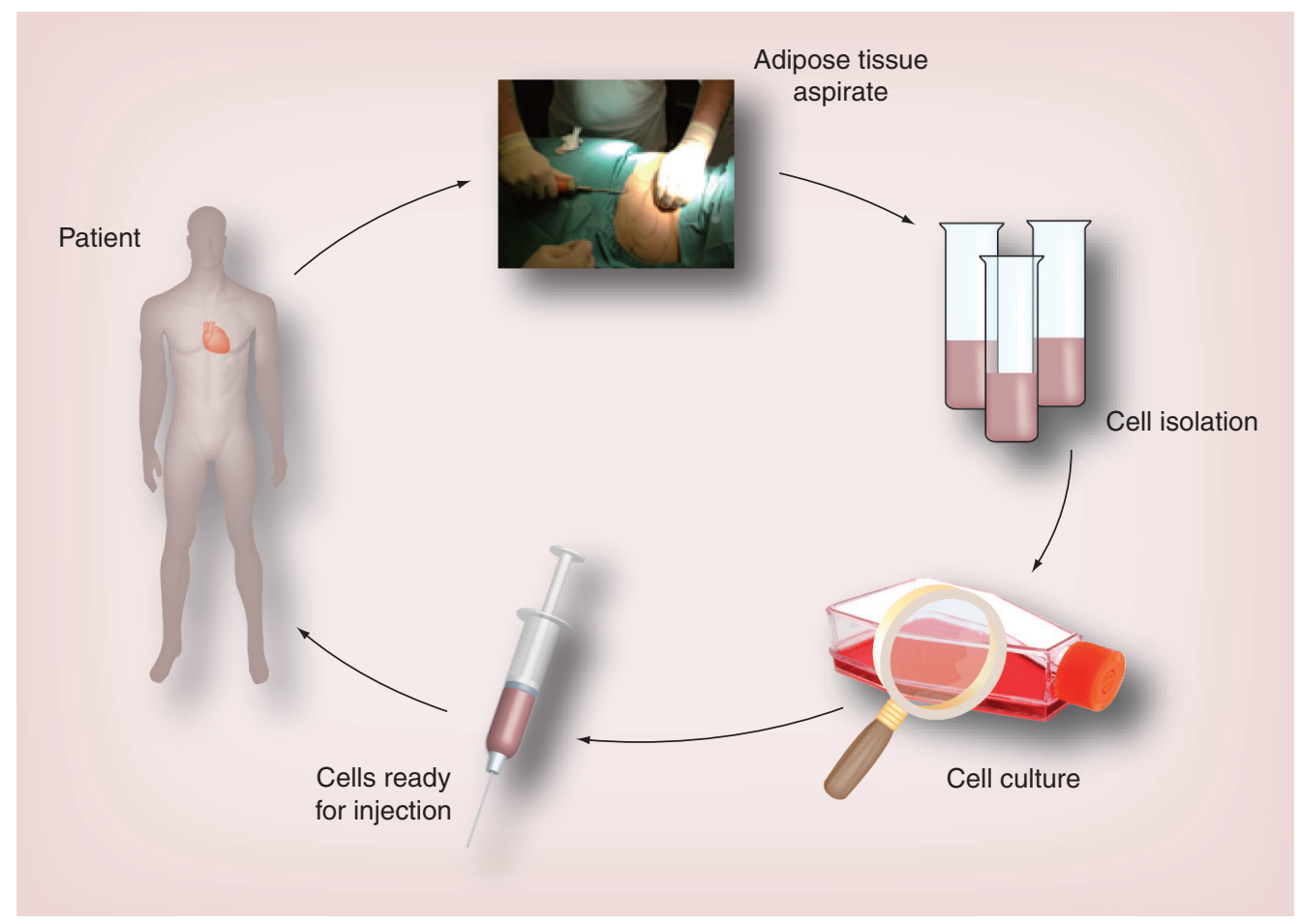

Figure 1. Overview of the process from liposuction to cell delivery. 


\section{Differentiation capacity of ADSCs}

Interest has been growing regarding the application of ADSCs for cell-based therapies such as tissue engineering because they possess the capacity to differentiate into different cell lineages. Several studies have demonstrated the ability of ADSCs to undergo differentiation when cultivated under lineage-specific conditions, along classical mesenchymal lineages, such as adipocytes [5], chondrocytes [16] and osteocytes [17]. Moreover, there is evidence for the ability of ADSCs to differentiate into other cell lines such as neurons [18], hepatocytes [19], smooth muscle cells [20], endothelial cells [9,21] and cardiomyocytes $[9,22,23]$.

\section{Animal studies}

Valina et al. studied the effect of intracoronarydelivered autologous ADSCs and bone marrow stromal cells (BMSCs) in pigs with acute myocardial infarction [24]. A total of 4 weeks after administration of ADSCs or BMSCs, immunohistochemical staining verified the presence of the injected cells in the left ventricle (LV). SPECT showed significant improvement in LV ejection fraction (LVEF) with both ADSCs and BMSCs, but only significant increases in wall thickness were found with ADSCs compared with BMSCs.

Mazo et al. studied the effect of intramyocardialtransplanted mice ADSCs, cardiac predifferentiated ADSCs and bone marrow mononuclear cells (BM-MNCs) in a rat model of chronic myocardial infarction [25]. Immunohistochemical staining verified the presence of ADSCs and bone marrow mononuclear cells in myocardium 1 week after the injection. However, the presence of these cells could not be detected after 4 weeks. Heart function was assessed by echocardiography and ${ }^{18} \mathrm{~F}-\mathrm{FDG}$ microPET imaging. Injection of BM-MNCs and AD-CMG did not induce a statistically significant change in LVEF compared with the control group. By contrast, transplantation of ADSCs was associated with a significant improvement in LVEF. However, transplantation of all cell types was associated with a reduced infarct size.

Wang et al. observed functional improvement of ischemic myocardium by treatment with intramyocardial-delivered ADSCs in rats [26]. ADSCs were labeled with superparamagnetic iron oxide and Lenti-GFP vectors before implantation. Superparamagnetic iron oxidecontaining GFP-labeled ADSCs were found in the infarct area. Moreover, a significantly higher LVEF as well as a thicker wall and smaller ischemic infarct area were found in ADSCtreated rats compared with untreated rats and rats treated with cell culture medium.

The hypothesis that human ADSC transplantation might contribute to cardiac functional recovery directly by transdifferentiation or indirectly by paracrine effects in rats with acute myocardial infarction was studied by Ii et al. [27]. Echocardiography performed 28 days after cell transplantation showed that LVEF and LV fractional shortening were significantly greater and regional wall motion score was significantly better in the ADSC group than in the placebo group. The ADSC group had significantly smaller infarct size and greater capillary density compared with the placebo group. These results suggest that transplantation of ADSCs preserved global and regional LV function, with the reduction of infarct size promoting neovascularization in ischemic myocardium after myocardial infarction. However, transdifferentiation of ADSCs into cardiac or vascular lineage cells was not observed; instead, they produced multiple proangiogenic chemokines and growth factors, such as VEGF, bFGF and SDF-1a. These factors may contribute to inducing angiogenesis and thereby improve cardiac tissue survival, reduce infarct size and recover cardiac function [27]. This has recently been supported by a study demonstrating that media from cultured ADSCs during hypoxia increase angiogenesis [28].

Consequently, the preclinical results suggest that ADSCs may be an ideal source for therapeutic angiogenesis in patients with chronic ischemic heart disease.

\section{MyStromalCell Trial}

The MyStromalCell Trial is a prospective, randomized, double-blind, placebo-controlled, single-center, Phase II study investigating the effects of VEGF-A $\mathrm{A}_{165}$-stimulated ADSCs in patients with chronic ischemic heart disease and refractory angina. The patients are randomized in a 2:1 ratio to receive ADSCs or placebo. The study is being conducted at the Department of Cardiology, The Heart Center, Rigshospitalet, Copenhagen, Denmark, and was launched in April 2010. The study protocol complies with the Declaration of Helsinki and is approved by the National Ethical Committee (02-268856) and Danish Medicines Agency (2612-2867).

\section{Patients}

Patients between 30 and 80 years of age with refractory myocardial ischemic symptoms and 
significant coronary artery stenoses visualized on a recent coronary angiogram are considered for the trial. These patients are considered for inclusion if they have ischemic symptoms despite maximal tolerable antianginal medication and have no further options for revascularization procedures, such as percutaneous coronary intervention and coronary artery bypass grafting (Box 1).

Patients are excluded if they suffer from severe heart failure (LVEF $<40 \%)$ or are known to have conditions other than angina, which could explain the symptoms of the patient, among other criteria (Box 2).

Furthermore, patients are excluded if they have a limited amount of abdominal adipose tissue excluding liposuction or if they are awaiting treatment for other disorders within the follow-up period. However, they will have the opportunity for reassessment after the treatment.

To be considered for inclusion, the patient must perform at least $25 \mathrm{~W}$ on a bicycle exercise test and not more than $125 \mathrm{~W}$, with estimated loads of 2.2 and 7.1 metabolic equivalents, respectively. However, the end of the exercise test must be due to myocardial ischemic symptoms. Otherwise, they will be excluded if they stop due to any other conditions such as claudicatio intermittens or knee or hip pain.

Before inclusion, all patients receive oral and written information about the study, and sign an informed consent form.

\section{Patient screening}

A coronary angiogram is required showing one or more significant stenoses with no options for revascularization. This decision is taken by at least two experienced interventional cardiologists.

\section{Box 1. Inclusion criteria for the MyStromalCell Trial.}

- Age between 30 and 80 years

- Moderate-to-severe angina (CCS angina class II-IV) or angina-equivalent dyspnea (NYHA class II-IV) despite optimal medical therapy

- Must have, within 12 months prior to entry, documented coronary angiographic evidence of significant vessel disease and at least one remaining larger coronary vessel from which new collaterals/vessels could be supplied

- Must not be eligible for any other revascularization procedures

- Left ventricular ejection fraction >40\% measured by echocardiography, SPECT, CT scan or MRI

- Duration of bicycle ergometry exercise tolerance tests: 2-10 min

- CABG or PCI within 6 months of entry and must have angiography performed at least 4 months after the previous intervention to rule out early restenosis

- Ventricular wall thickness of the treatment zone $>7 \mathrm{~mm}$ measured by echocardiography, CT scan or MRI

CABG: Coronary artery bypass grafting; CCS: Canadian Cardiovascular Society; NYHA: New York Heart Association; PCl: Percutaneous coronary intervention.
A clinical examination, history of the patient, 12-lead standard ECG, blood samples, spirometry, bicycle exercise test, Seattle Angina Questionnaire, weekly use of nitroglycerin, frequency of angina attacks, $\mathrm{x}$-ray of chest, cardiac computed tomography and cardiac MRI are performed.

If the patient still meets the inclusion criteria and has no exclusion criteria, then the patient is scheduled for liposuction.

\section{Liposuction}

An experienced plastic surgeon performs the liposuction manually with the patient under local anesthesia. Between 100 and $150 \mathrm{ml}$ of abdominal adipose tissue is obtained. After the abdominal liposuction, the patients have to wear an abdominal belt for 2 weeks to reduce the risk of bleeding and to inhibit the formation of knotty abdominal fibrotic tissue.

\section{Isolation of ADCs from liposuction aspirates}

A total of 100-150 $\mathrm{ml}$ of lipoaspirate obtained from each patient is washed two to three-times with phosphate-buffered saline (PBS) to remove residual blood and free lipids. The tissue is digested with collagenase NB 6 GMP grade, $0.3 \mathrm{U} / \mathrm{ml}$, dissolved in Hanks' balanced salt solution $\left(+\mathrm{CaCl}_{2}+\mathrm{MgCl}_{2}\right)$ diluted to a concentration of $2 \mathrm{mM}$ calcium at $37 \pm 1^{\circ} \mathrm{C}$ for $45 \mathrm{~min}$ while being gently turned. The collagenase is then neutralized with an equal amount of complete medium containing DMEM, low glucose (1 g/l) supplemented with $25 \mathrm{mM}$ hydroxyethyl piperazineethanesulfonic acid and L-glutamin, $10 \%$ fetal bovine serum pharma grade and $1 \%$ penicillin/streptomycin [29]. The digested tissue is filtered through a $100 \mu \mathrm{m}$ mesh to remove tissue remnants and is centrifugated at $1200 \mathrm{~g}$. The supernatant containing adipocytes is discharged and the cell pellet is resuspended in an appropriate volume of complete medium. ADCs are counted on a NucleoCounter ${ }^{\circledR}$ (Chemometec, Denmark) to evaluate the yield.

\section{- Cell culture}

The fresh isolated ADCs are plated at a density of $6 \times 10^{4} \mathrm{ADC} / \mathrm{cm}^{2}$ in $75 \mathrm{~T}$ culture flasks containing $15 \mathrm{ml}$ complete medium in humid air with $5 \% \mathrm{CO}_{2}$ at $37^{\circ} \mathrm{C}$.

After 2 days, when the cells are adhered, they are washed twice with PBS to remove all the nonadherent cells and the complete medium is changed. The complete medium is then subsequently changed every 3-4 days. The cells are 
passed once (P1) when they reach $80-90 \%$ confluence.

The safety of culture ADSC expansion is evaluated by testing the culture media for bacteria, yeast and mycoplasma 1 week before and on the day of treatment.

\section{Differentiation towards endothelial progenitor cells}

P1 ADSCs are stimulated to differentiate towards endothelial cells by culturing the cells for 7 days in VEGF- $\mathrm{A}_{165}$-stimulation medium. This is a modified complete medium containing only $2 \%$ fetal bovine serum and $50 \mathrm{ng} / \mathrm{ml}$ human recombinant VEGF-A ${ }_{165}$. The VEGF-A 165 -stimulation medium is changed every $2-3$ days.

If randomized to receive cell therapy, the ADSCs are suspended in PBS and $0.1 \%$ human albumin in a total volume of $3 \mathrm{ml}$. Otherwise, PBS with $0.1 \%$ human albumin is mixed with blood from the patient to a total volume of $3 \mathrm{ml}$ to blind the operator.

\section{- Cell transplantation}

Before the intramyocardial injection of ADSCs or placebo, a 3D electromechanical mapping of the $\mathrm{LV}$ is performed using the $\mathrm{NOGA}^{\circledR}$ map system (Biologics Delivery Systems, CA, USA) to identify the viable and nonviable areas of the myocardium [30-32]. With a NOGA-Myostar ${ }^{\circledR}$ catheter number $121120 \mathrm{~S}$, the ADSCs or placebo are delivered into the viable myocardium in 10-15 injections of $0.2 \mathrm{ml}$ each. After the procedure, echocardiography is performed to determine that no pericardial effusion or myocardial rupture has occured. Safety of injections and treatment with ADSCs are evaluated by registration of adverse and serious adverse events in the follow-up period.

\section{Follow-up}

The follow-up assessments are carried out after 4, 12 and 26 weeks and after 1, 2 and 3 years.

\section{End points \& enrollment data}

The primary end point is exercise tolerance testing 26 weeks after the treatment.

With an estimated enrollment of 60 patients, the statistic power will be more than $90 \%$ for the detection of an improvement in exercise tolerance testing of $60 \mathrm{~s}$ in the ADSC-treated group compared with the placebo group, with an expected standard deviation of $35 \mathrm{~s}$ and a $5 \% \alpha$-value.

Secondary end points are exercise tolerance testing after 12 weeks and 1, 2 and 3 years after the treatment, Canadian Cardiovascular Society

\section{Box 2. Exclusion criteria for the MyStromalCell Trial.}

- Pregnant or lactating women

- Clinically significant anemia, leukopenia, leukocytosis or thrombocytopenia

- Conditions other than angina that will limit exercise test (e.g., severe peripheral vascular disease, COPD or FEV1 <1)

- Immunocompromised status or currently receiving immunosuppressive therapy

- Valvular heart disease requiring surgical intervention

- Less than 6 weeks prior to screening: acute coronary syndrome with increase in CK-MB or troponins/PCI/CABG/stroke or TIA

- History of malignancy $<5$ years previously (except cured nonmelanoma skin cancer) or suspicion of current malignancy

- Other experimental medications within the last 4 weeks prior to the baseline ETT CABG: Coronary artery bypass grafting; COPD: Chronic obstructive pulmonary disease; ETT: Exercise tolerance test; FEV1: Forced expiratory volume in $1 \mathrm{~s}$; PCI: Percutaneous coronary intervention;

TIA: Transient ischemic attack.

and New York Heart Association functional class, Seattle Angina Questionnaire, weekly use of short-term nitroglycerin, frequency of angina attacks, LVEF, systolic and diastolic chamber sizes and myocardial perfusion measurements by CT and MRI (Box 3).

The study is ongoing and presently 25 patients are enrolled and being treated with either ADSCs or placebo in the study without any registered serious adverse events potentially related to the therapy.

\section{Discussion}

Preclinical studies indicate that ADSCs can differentiate into endothelial cells, and thus promote angiogenesis, or into cardiomyocytes, and thus replace the injured myocardium [24,27]. This theory of replacement and regeneration by transdifferentiation of ADSCs into tissuespecific cells has gradually been overtaken by the theory that it is the paracrine actions of stem cells that is leading to the replacement of injured tissue.

Animal studies demonstrate that after injecting ADSCs, they can be verified in myocardium

\section{Box 3. Outcome of the MyStromalCell Trial.}

- Primary outcome measures:

- Change from baseline in total exercise duration on exercise tolerance test using the bicycle ergometry test at 26 weeks after the treatment

- Secondary outcome measures:

- Symptoms (CCS and NYHA class, results of Seattle Angina Questionnaire, frequency of angina attacks and use of short-term nitroglycerin) after 3 and 6 months, and after 1, 2 and 3 years

- Change from baseline in total exercise duration on exercise tolerance test using the bicycle ergometry test after 3 months and after 1, 2 and 3 years

- Left ventricular ejection fraction

- Systolic and diastolic volumes

- Myocardial perfusion measured by PET, CT and MRI

CCS: Canadian Cardiovascular Society; CT: Computed tomography; NYHA: New York Heart Association. 
and lead to increased LVEF, reduced infarct size and greater capillary density $[24,25,27]$. However, the mechanisms behind their effect remain to be discovered.

In the perspective of cell-based angiogenesis, the PRECISE trial, a randomized, controlled clinical trial using ADCs, has recently been finalized, testing the direct effect of intramyocardial-delivered cells in 27 patients. This ADC solution is different from the ADSCs used in the present study, since ADCs are a mixture of adipose tissue cells with only a few ADSCs. To isolate and expand ADSCs, the ADCs have to be cultured to remove non-ADSC cell lines. The 6-month follow-up data were reported at the 7th International Symposium on Stem Cell Therapy and Cardiovascular Innovation in Madrid, Spain, in May 2010 [33]. The data showed a reduction in the extent of infarct size in the LV and a significant improvement in maximum oxygen consumption and patients' aerobic capacity measured as metabolic equivalents.

The APOLLO trial, a randomized, controlled clinical trial using intracoronary-delivered ADCs in patients with ST-elevation myocardial infarction, was presented at the same meeting [34]. In the 14 included patients, there was an improvement in LVEF, reduced infarct size and improved myocardial perfusion.

Losordo et al. recently published a randomized, double-blind, placebo-controlled, multicenter trial showing that intramyocardial injection of autologous CD34 $4^{+}$cells in 167 patients with refractory angina reduced the frequency of angina and improved exercise tolerance testing [35]. These very interesting results support an effect of stem cell therapy in refractory angina. However, comparative studies between CD $34^{+}$ cells and ADSCs are needed to investigate whether one cell line is superior to another.

In 31 patients with chronic myocardial ischemia and refractory angina, Friis et al. showed that intramyocardial injection of MSCs significantly improved patients' exercise capacity, LVEF, wall thickness and Seattle Angina Questionnaire evaluations, in addition to reducing ischemic symptoms and use of nitroglycerin consumption 6 months after the treatment [36]. There was a tendency towards improved outcome with increasing numbers of injected cells. These positive effects persisted at 1-year follow-up [37].

In another study, Friis et al. have also demonstrated that MSCs from healthy donors and from patients with known chronic coronary artery disease express the same surface markers and have similar proliferation capacities [38].
These impressive clinical results with MSCs from bone marrow in patients with refractory angina and the correlation between number of cells injected and clinical outcome point towards the use of larger cell numbers in future trials [36]. With this perspective, ADSCs isolated from abdominal tissue are an interesting cell source due to their similarities with MSCs and the high number of cells that can easily be harvested and culture expanded.

\section{Conclusion \& future perspective}

Over the next decades, chronic cardiac disease will cause a US $\$ 1$ billion loss in national income.

The costs of hospitalization due to angina, myocardial infarction and ischemic heart failure will increase because of the aging population. In addition, repetitive invasive interventions, improved medication and rehabilitation will also contribute to these increased costs.

In parallel with investigations of a potential beneficial clinical effect of stem cell therapies, new pharmacological treatments are evolving that might also reduce the need for regenerative medicine. However, with our present knowledge, these pharmacological therapies will only reduce symptoms and not restore damaged myocardium [39].

The regeneration of injured myocardium with stem cells is believed to improve quality of life and increase life expectancy. This treatment will lead to reduced symptoms, which may reduce expenditure on antianginal medication.

However, the differing outcomes in the previously published regenerative studies highlights the need to know more about how to optimize timing of treatment, cell characterization, source and type, dose, delivery methods and mechanisms of action, whether it be protein-, gene- or cell-based therapies $[2,40]$.

Pretreatment coating or upregulation of stem cell-specific adhesion molecules may be another target to increase the cells homing into the region of interest to minimize their postinjection wash-out due to myocardial blood flow.

Based on the preclinical studies and despite the limited amount of clinical trials, ADSCs are a potential source of cell-based therapy, which has been shown to be safe and feasible.

The improved outcome with increased numbers of stem cells [36] led us to this study setup. Some 100-300-fold more stromal cells are found in adipose tissue than in bone marrow.

Based on preclinical results, there is a need for conducting larger randomized, placebo-controlled 
clinical trials with ADSCs in patients with chronic myocardial ischemia and refractory angina to evaluate their safety and efficacy.

All of these issues will probably be solved at the end of this decade, and cell-based therapy with one or more cell lines will be offered as an experimental treatment for regenerative therapies. Moreover, the immunosuppressive effects of MSCs and ADSCs are also making them an attractive source of cells for organ transplantation purposes.

\begin{abstract}
Financial \& competing interests disclosure
The MyStromalCell Trial is supported financially by Danish

Agency for Science Technology and Innovation, and The

Capital Region of Denmark, Research Council. The authors

have no other relevant affiliations or financial involvement with any organization or entity with a financial interest in or financial conflict with the subject matter or materials discussed in the manuscript apart from those disclosed.

No writing assistance was utilized in the production of this manuscript.
\end{abstract}

\section{Executive summary}

\section{Background}

- Chronic cardiac disease will cause a US\$1 billion loss in national income.

- Some 100-300-fold more stromal cells are found in adipose tissue compared with bone marrow, making abdominal fat interesting as a source for harvesting mesenchymal stromal cells.

\section{Adipose-derived stromal cells}

- Adipose-derived stromal cells (ADSCS) have shown their capacity to differentiate into endothelial cells and cardiomyocytes.

- Animal studies have shown that ADSCs may increase left ventricular ejection fraction, reduce infarct size and increase capillary density.

\section{MyStromalCell Trial}

- The MyStromalCell Trial is a first-in-man, randomized, double-blind, placebo-controlled study to investigate whether VEGF-A ${ }_{165}{ }^{-}$ stimulated ADSCs obtained from abdominal adipose tissue increase exercise capacity in patients with chronic ischemic heart disease and refractory angina.

\section{Discussion}

- The optimal timing of treatment, delivery methods, mechanisms of the effect and cell source, type and dose still remain to be discovered.

\section{Conclusion \& future perspective}

- ADSCs may regenerate the injured myocardium, thereby reducing the symptoms and the use of antianginal medication.

- At the end of this decade, cell-based therapies will be widely used in cardiovascular disease.

"Besides their regenerative potential, the immunosuppressive effects of stem cells have promising prospects.

\section{References}

Papers of special note have been highlighted as:

- of interest

" " of considerable interest

1 Lopez AD, Mathers CD, Ezzati M, Jamison DT, Murray CJ. Global and regional burden of disease and risk factors, 2001: systematic analysis of population health data. Lancet 367(9524), 1747-1757 (2006).

2 Kastrup J. Stem cell therapy for cardiovascular repair in ischemic heart disease: how to predict and secure optimal outcome? EPMA J. 2(1), 107-117 (2011).

3 Mathiasen AB, Haack-Sørensen M, Kastrup J. Mesenchymal stromal cells for cardiovascular repair: current status and future challenges. Future Cardiol. 5(6), 605-617 (2009).

4 Lin CS, Xin ZC, Deng CH, Ning H, Lin G, Lue TF. Defining adipose tissue-derived stem cells in tissue and in culture. Histol. Histopathol. 25(6), 807-815 (2010).

5 Zuk PA, Zhu M, Mizuno H et al. Multilineage cells from human adipose tissue: implications for cell-based therapies. Tissue Eng. 7(2), 211-228 (2001).

6 Strem BM, Hicok KC, Zhu M et al. Multipotential differentiation of adipose tissue-derived stem cells. Keio J. Med. 54(3), 132-141 (2005).

7 Helder MN, Knippenberg M, Klein-Nulend J, Wuisman PI. Stem cells from adipose tissue allow challenging new concepts for regenerative medicine. Tissue Eng. 13(8), 1799-1808 (2007).

8 Bochev I, Elmadjian G, Kyurkchiev D et al. Mesenchymal stem cells from human bone marrow or adipose tissue differently modulate mitogen-stimulated B-cell immunoglobulin production in vitro. Cell Biol. Int. 32(4), 384-393 (2008).

9 Fraser JK, Schreiber R, Strem B et al. Plasticity of human adipose stem cells toward endothelial cells and cardiomyocytes. Nat. Clin. Pract. Cardiovasc. Med. 3(Suppl. 1), S33-S37 (2006).

10 Heydarkhan-Hagvall S, Schenke-Layland K, Yang JQ et al. Human adipose stem cells: a potential cell source for cardiovascular tissue engineering. Cells Tissues Organs 187(4), 263-274 (2008).

11 Lin K, Matsubara Y, Masuda Y et al. Characterization of adipose tissue-derived cells isolated with the Celution system. Cytotherapy 10(4), 417-426 (2008).

12 Katz AJ, Tholpady A, Tholpady SS, Shang H, Ogle RC. Cell surface and transcriptional characterization of human adipose-derived adherent stromal (hADAS) cells. Stem Cells 23(3), 412-423 (2005).

13 Zuk PA, Zhu M, Ashjian P et al. Human adipose tissue is a source of multipotent stem cells. Mol. Biol. Cell 13(12), 4279-4295 (2002).

14 Gronthos S, Franklin DM, Leddy HA, Robey PG, Storms RW, Gimble JM. Surface protein characterization of human adipose tissuederived stromal cells. J. Cell. Physiol. 189(1), 54-63 (2001)

15 Mitchell JB, McIntosh K, Zvonic S et al. Immunophenotype of human adipose-derived cells: temporal changes in stromal-associated 
and stem cell-associated markers. Stem Cells 24(2), 376-385 (2006).

16 Huang JI, Zuk PA, Jones NF et al. Chondrogenic potential of multipotential cells from human adipose tissue. Plast. Reconstr. Surg. 113(2), 585-594 (2004).

17 Weinzierl K, Hemprich A, Frerich B. Bone engineering with adipose tissue derived stromal cells. J. Craniomaxillofac. Surg. 34(8), 466-471 (2006).

18 Safford KM, Hicok KC, Safford SD et al. Neurogenic differentiation of murine and human adipose-derived stromal cells. Biochem. Biophys. Res. Commun. 294(2), 371-379 (2002).

19 Stock P, Staege MS, Muller LP et al. Hepatocytes derived from adult stem cells. Transplant. Proc. 40(2), 620-623 (2008).

20 Wang C, Yin S, Cen L et al. Differentiation of adipose-derived stem cells into contractile smooth muscle cells induced by transforming growth factor-betal and bone morphogenetic protein-4. Tissue Eng. Part A 16(4), 1201-1213 (2010).

21 Planat-Benard V, Silvestre JS, Cousin B et al. Plasticity of human adipose lineage cells toward endothelial cells: physiological and therapeutic perspectives. Circulation 109(5), 656-663 (2004).

22 Planat-Benard V, Menard C, Andre M et al. Spontaneous cardiomyocyte differentiation from adipose tissue stroma cells. Circ. Res. 94(2), 223-229 (2004).

23 Strem BM, Zhu M, Alfonso $Z$ et al. Expression of cardiomyocytic markers on adipose tissue-derived cells in a murine model of acute myocardial injury. Cytotherapy 7(3), 282-291 (2005).

24 Valina C, Pinkernell K, Song YH et al. Intracoronary administration of autologous adipose tissue-derived stem cells improves left ventricular function, perfusion, and remodelling after acute myocardial infarction. Eur. Heart J. 28(21), 2667-2677 (2007).

"I First study showing that intracoronarydelivered adipose-derived stem cells engraft into the infarcted region of the myocardium and improve cardiac function.

25 Mazo M, Planat-Benard V, Abizanda G et al. Transplantation of adipose derived stromal cells is associated with functional improvement in a rat model of chronic myocardial infarction. Eur. J. Heart Fail. 10(5), 454-462 (2008).
26 Wang L, Deng J, Tian W et al. Adiposederived stem cells are an effective cell candidate for treatment of heart failure: an MR imaging study of rat hearts. Am. J. Physiol. Heart Circ. Physiol. 297(3), H1020-H1031 (2009).

27 Ii M, Horii M, Yokoyama A et al. Synergistic effect of adipose-derived stem cell therapy and bone marrow progenitor recruitment in ischemic heart. Lab. Invest. 91(4), 539-552 (2011).

28 Rasmussen JG, Frobert O, Pilgaard L et al. Prolonged hypoxic culture and trypsinization increase the pro-angiogenic potential of human adipose tissue-derived stem cells. Cytotherapy 13(3), 318-328 (2011).

29 Haack-Sørensen M, Friis T, Bindslev L, Mortensen S, Johnsen HE, Kastrup J. Comparison of different culture conditions for human mesenchymal stromal cells for clinical stem cell therapy. Scand. J. Clin. Lab. Invest. 68(3), 192-203 (2008).

30 Baldazzi F, Jorgensen E, Ripa RS, Kastrup J. Release of biomarkers of myocardial damage after direct intramyocardial injection of genes and stem cells via the percutaneous transluminal route. Eur. Heart J. 29(15), 1819-1826 (2008).

31 Kastrup J, Jorgensen E, Ruck A et al. Direct intramyocardial plasmid vascular endothelial growth factor- $\mathrm{A}_{165}$ gene therapy in patients with stable severe angina pectoris $\mathrm{A}$ randomized double-blind placebo-controlled study: the Euroinject One trial. J. Am. Coll. Cardiol. 45(7), 982-988 (2005).

32 Ripa RS, Wang Y, Jorgensen E, Johnsen HE, Hesse B, Kastrup J. Intramyocardial injection of vascular endothelial growth factor- $\mathrm{A}_{165}$ plasmid followed by granulocyte-colony stimulating factor to induce angiogenesis in patients with severe chronic ischaemic heart disease. Eur. Heart J. 27(15), 1785-1792 (2006).

33 Perin E, Fernández-Aviles F. Freshly adipose-derived stem cells in chronic ischaemia. The PRECISE Trial. Presented at: 7th International Symposium on Stem Cell Therapy and Cardiovascular Innovation. Madrid, Spain, 7 May 2010.

34 Duckers E. Freshly adipose-derived stem cells in acute myocardial infartion. The APOLLO Trial. Presented at: 7th International Symposium on Stem Cell Therapy and Cardiovascular Innovation. Madrid, Spain, 7 May 2010.
35 Losordo DW, Henry TD, Davidson C et al. Intramyocardial, autologous $\mathrm{CD} 34^{+}$cell therapy for refractory angina. Circ. Res. 109(4), 428-436 (2011).

36 Friis T, Haack-Sørensen M, Mathiasen AB et al. Mesenchymal stromal cell derived endothelial progenitor treatment in patients with refractory angina. Scand. Cardiovasc. J. 45(3), 161-168 (2011).

"- First-in-man trial using intramyocardialdelivered autologous mesenchymal stromal cells in patients with stable coronary artery disease and refractory angina, showing significant improvement in left ventricular function and exercise capacity, in addition to an improvement in clinical symptoms and Seattle Angina Questionnaire evaluations at 6-month follow-up.

37 Haack-Sørensen M, Friis T, Mathiasen AB et al. Direct intramyocardial mesenchymal stromal cell injections in patients with severe refractory angina - one year follow-up. Cell Transplant. (2012) (In Press).

" First-in-man trial using intramyocardialdelivered autologous mesenchymal stromal cells in patients with stable coronary artery disease and refractory angina, showing significant improvement in left ventricular function and exercise capacity, in addition to an improvement in clinical symptoms and Seattle Angina Questionnaire evaluations at 1-year follow-up, with a tendency towards improved outcome with increasing numbers of cells injected.

38 Friis T, Haack-Sørensen M, Hansen SK, Hansen L, Bindslev L, Kastrup J. Comparison of mesenchymal stromal cells from young healthy donors and patients with severe chronic coronary artery disease. Scand. J. Clin. Lab. Invest. 71(3), 193-202 (2011).

39 Manchanda A, Aggarwal A, Aggarwal N, Soran O. Management of refractory angina pectoris. Cardiol. J. 18(4), 343-351 (2011).

- Review concerning how to manage patients with refractory angina.

40 Kastrup J. Gene therapy and angiogenesis in patients with coronary artery disease. Expert Rev. Cardiovasc. Ther. 8(8), 1127-1138 (2010).

\section{Website}

101 ClincialTrials.gov. www.clinicaltrials.gov 